\title{
Malaysian researchers bet big on home-grown Viagra
}

For the first few days you might have a light headache, a slight fever or even a rash. But the results-increased sexual desire, enhanced performance and general well-being-should be worth it. At least, that's what Malaysia's researchers are banking on.

Malaysians have long believed that consuming tongkat ali, a shrub that can grow to ten meters, has several benefits - most notably, aphrodisiac powers for men. Scientists there now hope to hone in on the herb's active ingredients and market it to the world. If they succeed, the venture will mark Malaysian biotechnology's first big triumph.

Most Malays ingest the herb, Eurycoma longifolia, as a tea prepared by boiling chunks of the root. More recently, a powder produced by drying the boiled concoction is being put into pills or added to food products. In Kuala Lumpur, billboards advertise canned beverages spiked with the herb; tongkat ali chocolate and dried coffee are available at airport shops. There are nearly 200 such products on the domestic market.

These products are ready to go abroad, says Azizol Abdul Kadir, president of Phytes Biotek, a biotechnology company in Selangor. "I'll put tongkat ali on the world market."

Malaysia's neighbor Singapore has won global acclaim for its burgeoning biomedical research industry. In a bid to jumpstart its own ailing biotechnology industry (Nature 436, 620-621; 2005), the Malaysian government has sunk about $\$ 7$ million into the herb. The central project is a collaboration with 230 researchers at the Massachusetts Institute of Technology (MIT), the Forest Research Institute of Malaysia and 16 other Malaysian institutes.

Critics say Malaysia is squandering its scarce resources on research that is unlikely to pay off. "Basic science should be equally emphasized, but it isn't," says a biologist at Monash University Malaysia in Selangor.

The researchers have had some success (Plant Physiol. 131, 1294-1301; 2003), but have not yet published reports on the herb's efficacy in high-impact journals. That is because the government is concerned about intellectual property, says Mohd. Ilham Adenan, the project's coordinator. The researchers have already filed patents in Malaysia, the US and Japan.

The project suffered at least a temporary setback on 12 August, when the US rejected an application for a patent on a 4.3-kilodalton glycoprotein thought to increase testosterone synthesis. But MIT plant biologist Anthony Sinskey remains bullish. "The findings are novel and important so we are confident," he says.

The researchers decline to identify the protein, one of the herb's active components. Previous studies have shown that in mice, gradually increasing the herb's dose makes mice more sexually active (J. Herbs Species Med. Plants 9, 109-114; 2002). Beyond a set dose, the males are overcome with sexual desire, says Azizol, and "don't discriminate between male and female anymore."

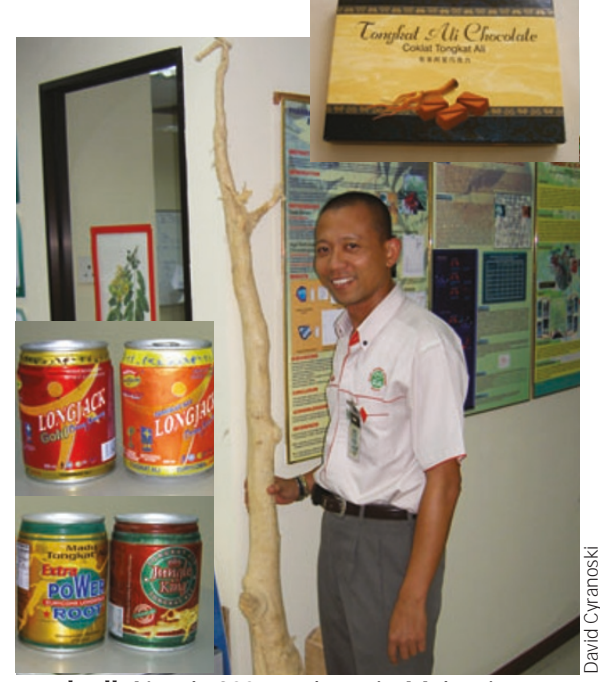

Hard sell: Nearly 200 products in Malaysia are made with the tongkat ali root, thought to have aphrodisiac properties.

The results have also borne out in early clinical studies out on a small group of men, Azizol says. In one study, $40 \%$ reported feeling easily aroused, having longer erections and experiencing more climaxes during intercourse. Many also reported improved memory and better bowel movements. But $12 \%$ noted constipation and $8 \%$ said their erectile problems persisted.

Azizol says the herb might also become popular for combating malaria, cancer and aging. "It's not just for sex-it's for the whole body."

David Cyranoski, Tokyo

\section{Complaints of gender bias compel NIH to revise awards scheme}

When the US National Institutes if Health (NIH) announced the winners of the first annual NIH Director's Pioneer Award last year, one fact stood out: all nine awardees were men. This year, thanks to a flurry of protests from scientists, the winners are likely to be a more diverse bunch.

Shortly after the announcement of last year's winners in September 2004, individual scientists and groups such as the American Society for Cell Biology (ASCB) and the Association for Women in Science complained about the "striking lack of diversity."

"The selection of such a homogeneous group of award winners sends an unavoidable message to women that they are not worthy of recognition as 'pioneers' and indeed may be considered less valued than men by the highest levels of the NIH," wrote ASCB's then-president Harvey Lodish and Women in Cell Biology chair Ursula Goodenough.

In response, the NIH transferred responsibility for the awards from the director's office - which had little experience with grants - to the National Institute of General Medical Sciences. The agency also named Jeremy Berg, the institute's directorand one of several NIH researchers who complained-to redesign the program.

Together with Nora Volkow, director of the National Institute on Drug Abuse, and NIH researcher Judith Greenberg, Berg redesigned the award scheme to include more women and minorities as both applicants and judges.

"I was impressed with the changes they made, this should be a model for other grant application processes," says Stanford University neuroscientist Ben Barres (see page 916), who has served as a judge both years.

The changes are significant: up to $40 \%$ of this year's referees are women or minorities, and applicants can nominate themselves. Last year, by contrast, 60 of the 64 judges were men and "unconscious bias" probably affected the outcome, notes Barres. "Applicants had to be nominated-people tend to nominate men for these things," he says.

The awards, worth up to $\$ 500,000$ for five years, aim to support creative and novel approaches to biomedical research. The 2005 winners are set to be announced 29 September.

This year's applications have been reworded to say that women and members of underrepresented groups are "especially encouraged" to apply, and that the award is available to early- and mid-career scientists.

According to Berg, $26 \%$ of this year's applicants are female, and the breakdown for the 20 finalists reflects the applicant pool. In 2004 , women made up only $21 \%$ of the 1,300 applicants and only 2 of the 21 finalists. Because the award is given to researchers for novel biomedical research strategies, it attracts applicants with technical and engineering backgrounds, fields that have fewer women, says Berg. The NIH does not have data on the status of minority applicants.

Kris Novak, San Francisco 